\title{
Occurrence and Sources of Triterpenoid Methyl Ethers and Acetates in Sediments of the Cross-River System, Southeast Nigeria
}

\author{
Orok E. Oyo-Ita, ${ }^{1}$ Bassey O. Ekpo, ${ }^{1}$ Daniel R. Oros, ${ }^{2}$ and Bernd R. T. Simoneit ${ }^{3,4}$ \\ ${ }^{1}$ Department of Pure and Applied Chemistry, University of Calabar, P.M.B. 1115 Calabar, Nigeria \\ ${ }^{2}$ Consultant 72 Marina Lakes Drive, Richmond, CA 94804, USA \\ ${ }^{3}$ Department of Chemistry, Oregon State University, Corvallis, OR 97331, USA \\ ${ }^{4}$ COGER, King Saud University, Riyadh 11451, Saudi Arabia
}

Correspondence should be addressed to Orok E. Oyo-Ita, orokoyoita@yahoo.com

Received 6 November 2009; Revised 18 January 2010; Accepted 19 January 2010

Academic Editor: Peter A. Tanner

Copyright ( $\odot 2010$ Orok E. Oyo-Ita et al. This is an open access article distributed under the Creative Commons Attribution License, which permits unrestricted use, distribution, and reproduction in any medium, provided the original work is properly cited.

\begin{abstract}
Pentacyclic triterpenol methyl ethers (PTMEs), germanicol methyl ether (miliacin), 3-methoxyfern-9(11)-ene (arundoin), $\beta$ amyrin methyl ether (iso-sawamilletin), and 3-methoxytaraxer-14-ene (sawamilletin or crusgallin) were characterized in surface sediments of the Cross-River system using gas chromatography-mass spectrometry (GC-MS). Triterpenol esters (mainly $\alpha$ - and $\beta$-amyrinyl acetates and hexanoates, and lupeyl acetate and hexanoate) were also found. These distinct compounds are useful for assessing diagenesis that can occur during river transport of organic detritus. Poaceae, mainly Gramineae and Elaeis guineensis higher plant species, are proposed as primary sources for the PTMEs and esters in the sediments. PTMEs are biomarkers of specific higher plant subspecies, while the triterpenol esters are indicators of early diagenetic alteration of higher plant detritus.
\end{abstract}

\section{Introduction}

Pentacyclic triterpenoids have generally been utilized as biomarkers to trace genetic sources of organic matter in sedimentary environments, petroleum exploration, or paleoenvironmental reconstructions of biome changes that document climate change [1-4]. The oleananes, ursanes, fernanes, lupanes, and their derivatives, widely distributed mainly as the oxygenated forms in many varieties of higher plant species, belong to this class of compounds [4-10]. Their characterization in chemotaxonomic studies can provide key information of flora changes [11]. Their tendencies to also resist biodegradation and occurrence in sediments suggest the potential application as specific higher plant derived biomarkers $[9,10]$. However, reports of pentacyclic triterpenol methyl ethers (PTMEs) in sedimentary environments are limited to lakes $[2,4,12]$. Other reports have assessed sedimentary input of terrestrial and/or planktonic organic matter with triterpenoid natural products (e.g., [13-15]) and biomass source tracers to smoke aerosols (e.g., burning of sugar cane [16]). Reports of triterpenoid esters in sediments are also limited, because typical extract analyses generally involved saponification as a preparative step. Plant wax analyses without hydrolysis do reveal triterpenol esters as part of the wax esters in epicuticular waxes (e.g., $[17,18])$.

Under aerobic conditions, the transformation of plantderived triterpenoids often involves oxidation, dehydration, hydrolysis, decarboxylation, ring opening, and aromatization reactions [19]. For instance, in coal forming environments, higher plant triterpenoids generally undergo aromatization starting from ring $\mathrm{A}$, triggered by the elimination of the oxygenated functionality at C-3 and proceeding to rings $\mathrm{D} / \mathrm{E}$ [20-22]. The PTMEs, which are natural products, appear to be more resistant to environmental alteration than the triterpenol esters and thus may be good biomarkers. Triterpenol esters, on the other hand, may be useful for assessing early diagenesis (i.e., hydrolysis) of 
terrestrial higher plant detritus during river transport. It is the aim of this paper to report on the characterization, occurrence, and sources of PTMEs and triterpenol esters in surface sediments of the Cross-River system, Nigeria. These are minor compounds occurring with the dominant triterpenoids such as taraxerol, amyrin, and lupeol.

\section{Locale Description}

The characteristic features of the study area are summarized in Table 1 and the sampling locations of surface sediments are shown in Figure 1. The Cross-River system is one of the largest estuaries located in the eastern edge of the Niger Delta. The whole Cross-River system lies approximately between longitudes $2^{\circ} 03^{\prime} \mathrm{E}$ and $10^{\circ} 00^{\prime} \mathrm{E}$ and latitudes $4^{\circ} 00^{\prime} \mathrm{N}$ and $8^{\circ} 00^{\prime} \mathrm{N}$ and covers an area of $54,000 \mathrm{~km}^{2}$, of which $14,000 \mathrm{~km}^{2}$ lies in Cameroon and $39,000 \mathrm{~km}^{2}$ lies in Nigeria. The river is formed from numerous tributaries arising from the western slopes of the Cameroon Mountains. It flows southwest into the Atlantic Ocean with a discharge rate between 879 and $2533 \mathrm{~m}^{3} / \mathrm{sec}$ [23]. The system is exposed to temporal flooding depending on the tides and the season (wet versus dry) and has large fluctuations in hydrographic conditions [23]. The river system is characterized by the interaction of an estuarine and freshwater-seawater frontal system seaward of the river mouth (typical of a deltaic coastal region) with tidal and wind-driven surface currents. Previous studies focused mainly on fisheries [24], ecology [25], water quality [26], hydrology of the lower Cross-River [23], and hydrocarbons in sediments $[27,28]$.

\section{Experimental Methods}

Sampling stations were chosen to cover the characteristic features of the river environment as summarized in Table 1. Sediments were collected in January 1999 (dry season) with a Van Veen grab sampler $\left(0.1 \mathrm{~m}^{2}\right)$, wrapped with aluminum foil and stored frozen at $-4^{\circ} \mathrm{C}$ until analysis. Freeze-dried sediments were grounded in a disc mill and subsequently sieved to pass 230 mesh to obtain the $<63 \mu \mathrm{m}$ fraction. Extraction and fractionation of the $<63 \mu \mathrm{m}$ fraction were as previously reported by Ekpo et al. [29]. Briefly, $50 \mathrm{~g}$ dry samples were extracted in a Soxhlet apparatus with dichloromethane and methanol $(2: 1)$. Extracts were concentrated, desulfurized (activated $\mathrm{Cu}$ ), and fractionated by column chromatography on activated silica and alumina. The saturated fraction (F1) was eluted with hexane, the aromatic fraction (F2) with dichloromethane, and the nitrogensulfur-oxygen (NSO) containing polar fraction (F3) with dichloromethane-methanol. All fractions were reduced in volume and dried aliquots were weighed for quantitation. Total organic carbon (TOC) analyses for all sediment samples were obtained using an LECO C-S-444 analyser.

Gas chromatography-mass spectrometry (GC-MS) analyses of the isolated fractions were performed on a HewlettPackard Model 6890 GC coupled to a Hewlett-Packard Model 5973 quadrupole MSD. Separation was achieved on a DB5-MS column $(30 \mathrm{~m} \times 0.25 \mathrm{~mm}$ i.d., $0.25 \mu \mathrm{m}$ film thickness). The GC operating conditions were as follows. Temperature holds at $65^{\circ} \mathrm{C}$ for 2 minutes, increases from 65 to $300^{\circ} \mathrm{C}$ at a rate of $6^{\circ} \mathrm{C} \mathrm{min}^{-1}$, and with final isothermal holds at $300^{\circ} \mathrm{C}$ for 20 minutes. Helium was used as carrier gas. The sample was injected in the splitless mode with the injector temperature at $300^{\circ} \mathrm{C}$. The mass spectrometer was operated in the electron impact mode at $70 \mathrm{eV}$ ionization energy and scanned from 50 to 650 Dalton. Data were acquired and processed using ChemStation software. Compounds were identified by comparison with literature data and interpretation of mass spectrometric fragmentation patterns.

\section{Results and Discussion}

The analytical results are presented in Table 1 . The percentage of total organic carbon (TOC) contents in the sediments ranged between $1.3 \%$ and $4.6 \%$, while the extractable organic matter $(\mathrm{EOM})$ ranged between 1.1 and $4.1 \mathrm{~g} / \mathrm{kg}$ dry weight $(\mathrm{dw})$. The total hydrocarbons determined from $\mathrm{F} 1$ and $\mathrm{F} 2$ fractions showed the lowest concentration range in sediments from the upper river region (range $2-44 \mathrm{mg} / \mathrm{kg} \mathrm{dw}$ ), a moderate concentration range in sediments from the middle region (range $60-148 \mathrm{mg} / \mathrm{kg} \mathrm{dw}$ ), and the highest concentration range in sediments from the lower deltaic region of the estuary $(185-511 \mathrm{mg} / \mathrm{kg} \mathrm{dw}$ ) (Table 1). The data for the Upper Calabar River and Great Kwa River are given as ranges and averages (Table 1).

4.1. Mass Spectrometry. Pentacyclic triterpenol methyl ethers (PTMEs) in the bottom sediments were monitored with the $m / z 440$ key ion $\left(\mathrm{M}^{+}\right)$in the MS data. Examples are shown in Figure 2 and the mass spectra of the major PTMEs are also given. Their concentrations range from 0.02 to $2.4 \mathrm{mg} / \mathrm{kg} \mathrm{dw}$ (Table 1). The fragment ion at $m / z 408$ (M-32, minor) and $\mathrm{m} / \mathrm{z} 393$ (M-15-32) indicates loss of the methoxy group as methanol during fragmentation [30]. Compound 1 has a base peak at $m / z 189$ and accompanying ions at $m / z 177$ and 204 , which are characteristic for germanicol (olean-18-en$3 \beta$-ol). Thus the mass spectrum fits with the methyl ether of germanicol (miliacin). Compound 2 has a base peak at $\mathrm{m} / \mathrm{z} 204$ which is from the D/E ring of taraxerene after retro-Diels-Alder rearrangement [31]. The additional ions at $\mathrm{m} / \mathrm{z} 316,301,284,269,257,218$, and 189 are characteristic for taraxerol methyl ether. Compound 3 exhibits a different fragmentation pattern, with significant fragments at $\mathrm{m} / \mathrm{z} 425$ (base peak), 393, 273, 241, and 71. The prominent fragment ion at $m / z 393$ (M-15-32) indicates loss of a methyl group followed by methanol, and $\mathrm{m} / \mathrm{z} 273$ (M-167) fission of ring $\mathrm{C} / \mathrm{D}$ and loss of the ring $\mathrm{E}$ moiety with the isopropyl group, typical of the fernene type and is assigned as fern-9(11)-en$3 \beta$-ol methyl ether [32]. The mass spectrum of compound 4 has a base peak at $\mathrm{m} / z 218$ and intense ions at $\mathrm{m} / \mathrm{z} 191$ and 203 , which, with the $\mathrm{M}^{+}$at $m / z 440$ and the typical fragments at $\mathrm{m} / \mathrm{z} 425,408$, and 393 indicate $3 \beta$-methoxyolean-12-ene ( $\beta$-amyrin methyl ether or iso-sawamilletin). These mass spectra are also good fits with those reported by Jacob et al. [4]. 


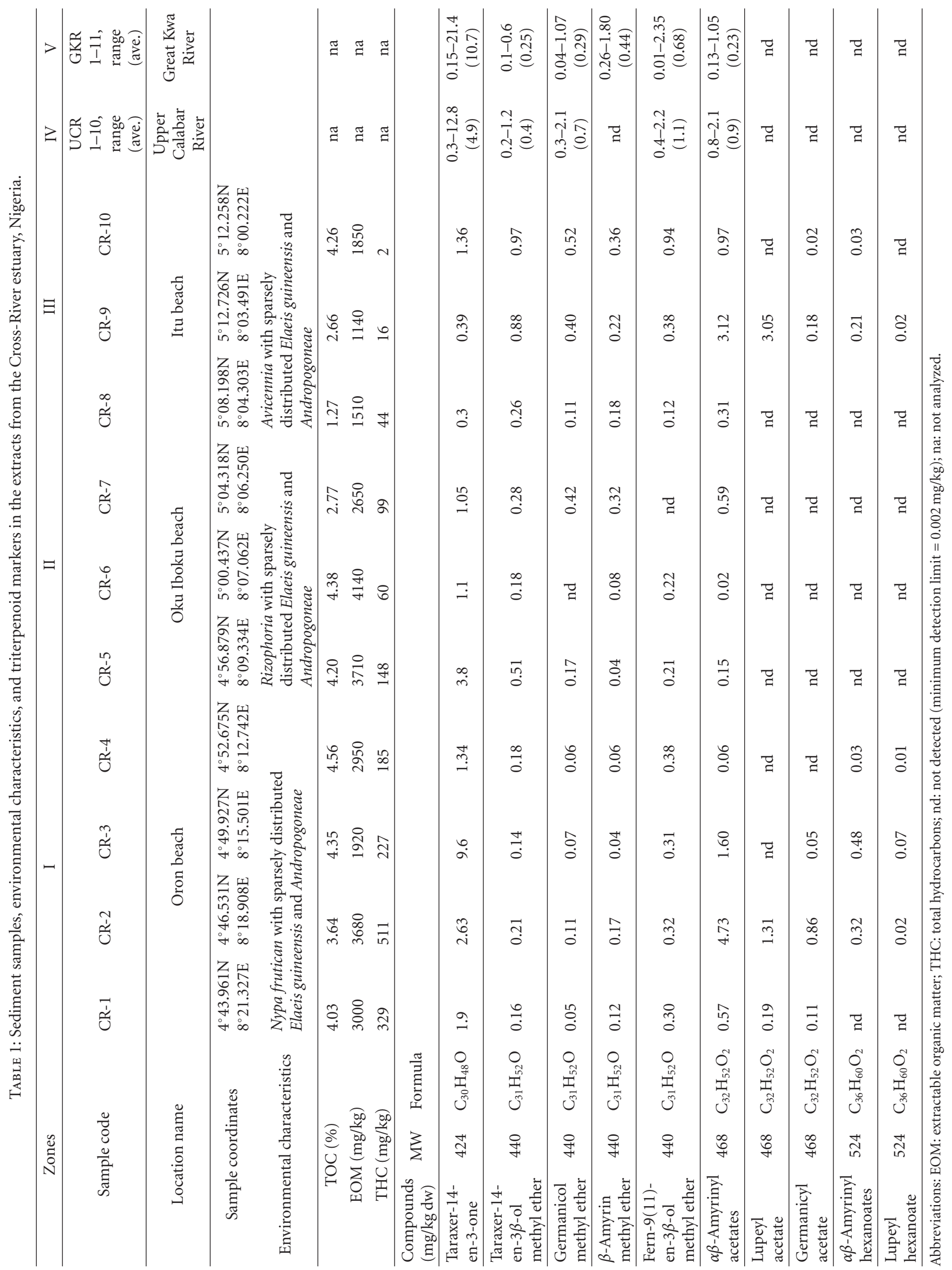




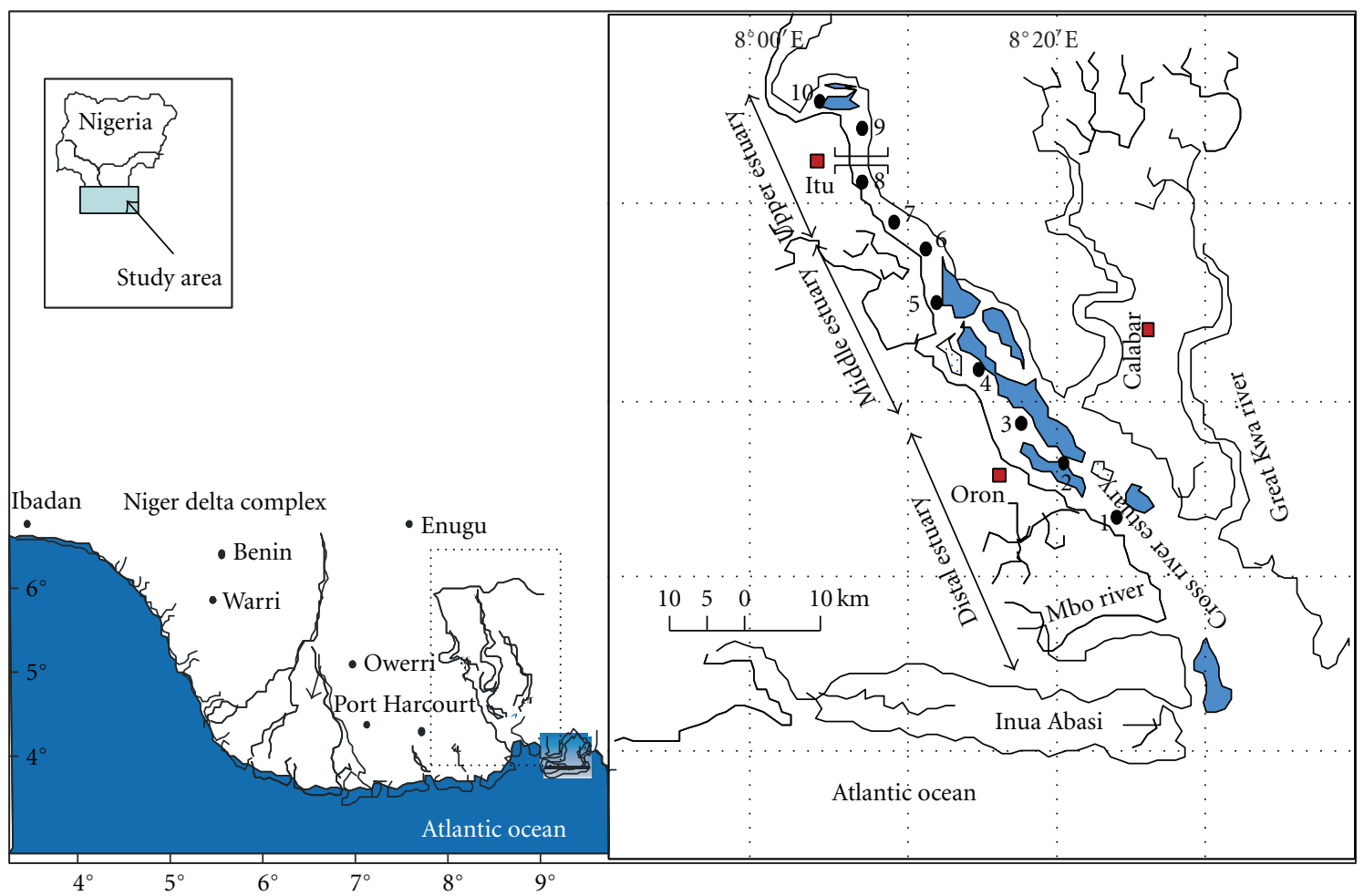

Figure 1: Map of the southeastern part of the Niger Delta of Nigeria showing the sampling locations in the Cross-River estuary.

Examples of MS data for the triterpenol esters are shown in Figure 3. The mass spectra of the esters are quite simple, reflecting the fragmentation pattern of the triterpane skeleton with minor ions from the additional acid moiety [33]. Thus, the key ion for the amyrin esters is $m / z 218$ and the mass spectrum of $\beta$-amyrinyl acetate consists of the $\mathrm{M}^{+}$ at $m / z 468$, loss of $\mathrm{CH}_{3}$ to $\mathrm{m} / z 453$, and loss of the acetic acid after $\mathrm{H}$ transfer to $m / z 408$ (Figures 3(a) and 3(b), resp.). The amyrinyl hexanoates (e.g., Figure $3(\mathrm{c})$ for $3 \beta$-isomer) have $\mathrm{M}^{+}$at $m / z 524$, followed by loss of $\mathrm{CH}_{3}$ or the acid moiety to $m / z 509$ and 408 , respectively. The mass spectra of lupeyl acetate (Figure 3(d)) and lupeyl hexanoate (Figure 3(e)) also exhibit the dominant fragmentation pattern of the lupene skeleton and the acid moiety is reflected in the $\mathrm{M}^{+}, \mathrm{M}-\mathrm{CH}_{3}$, and $\mathrm{M}$-acid ions. The mass spectrum of germanicyl acetate (Figure 3(f)) has the characteristic fragments for oleana2,18-diene with significant $\mathrm{M}^{++}$at $\mathrm{m} / \mathrm{z} 468$, and $\mathrm{M}_{-} \mathrm{CH}_{3}$ to $\mathrm{m} / z 453$ and a minor loss of acetic acid to $\mathrm{m} / \mathrm{z} 408$. The concentrations of the triterpenol esters range from not detectable to a total of $7.2 \mathrm{mg} / \mathrm{kg}$ (Table 1).

4.2. Sources and Fate. The detection of these PTMEs in relatively few sedimentary environments may be linked to variation in environmental conditions such as seasonal and environmental differences that determine the biosynthesis of these compounds in specialized tissues of certain species of higher plants [4]. Nevertheless, the PTMEs are natural products introduced directly to the river in organic detritus, probably in leaf litter. The primary sources of PTMEs in this estuary may be from monocotyledonous plants belonging to the Gramineae, on the basis of taxonomic identifications in the vicinity of the study area. According to Jacob et al. [4] plants belonging to the Poaceae produce iso-sawamilletin, miliacin, arundoin, and sawamilletin and thus could also contribute to the sources of PTMEs in these sediments. For instance, the occurrence of nine PTMEs from numerous species of Gramineae has been reported (e.g., [30, 34]) and arundoin was found in palm trees, Elaeis guineensis [35], and most Poaceae reviewed by Jacob et al. [4].

The persistence of these PTMEs in this estuary may reflect their relative stability to aerobic degradation. We see no evidence that these PTMEs have undergone diagenetic transformations to the $3 \alpha$-PTMEs [4] in the sediments. Taraxerone also reported for reference (Table 1) was detected at almost all the sampling stations. It is a product from the aerobic oxidation of taraxerol from mainly a mangrove origin and a major natural product in most of these samples (Table 1) (e.g., [6, 36-38]). Thus, the relative capacity of these PTMEs to resist biodegradation may enhance their utility as biomarkers for source correlations of specific higher plant subspecies in environmental samples.

The triterpenol esters in these sediments are mainly acetates and lesser amounts of hexanoates (Table 1). However, based on previous studies of triterpenoid esters in vegetation and sediments (palmitates, stearates, etc., [17, $18]$ ), it is possible that there are even higher molecular weight esters present in these sediments. They are known to elute at much higher GC temperatures and are not detectable by this analytical protocol. The concentrations of the esters are low 


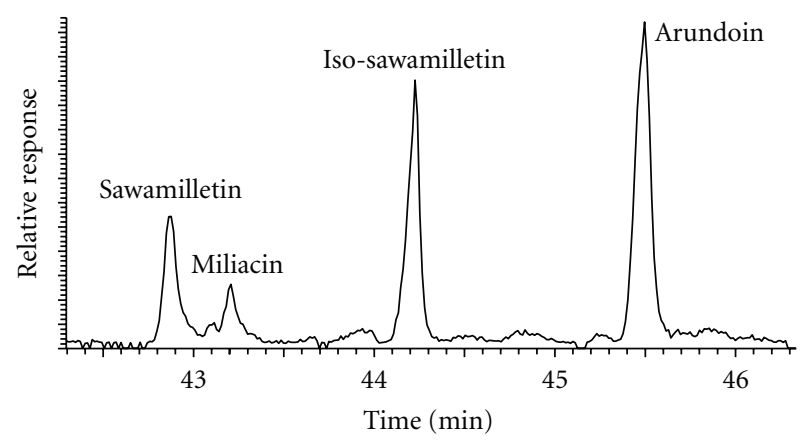

(a)

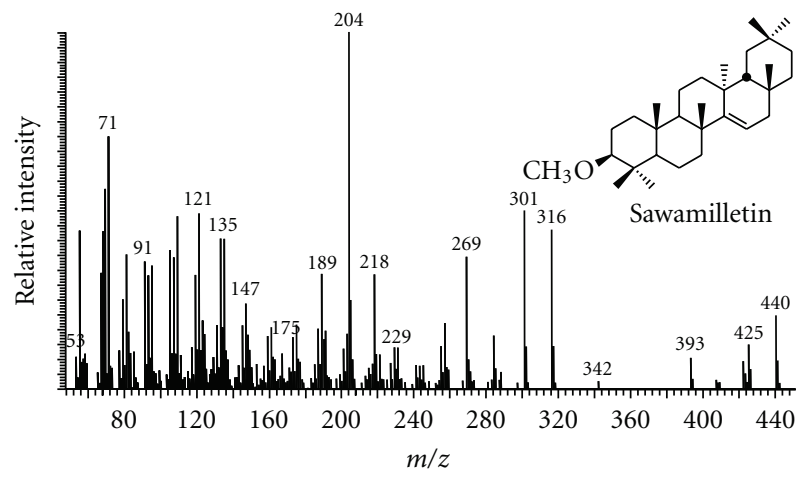

(c)

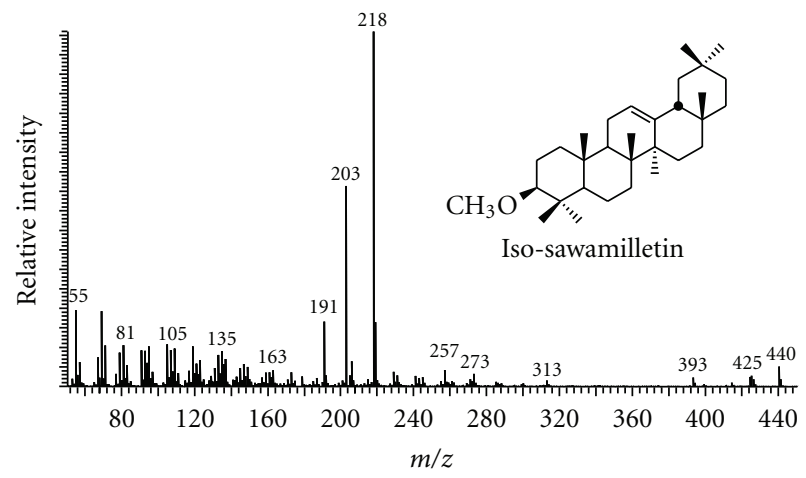

(e)

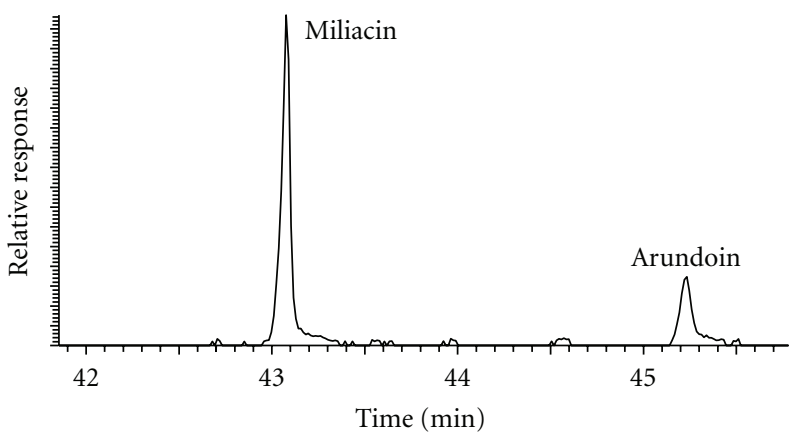

(b)

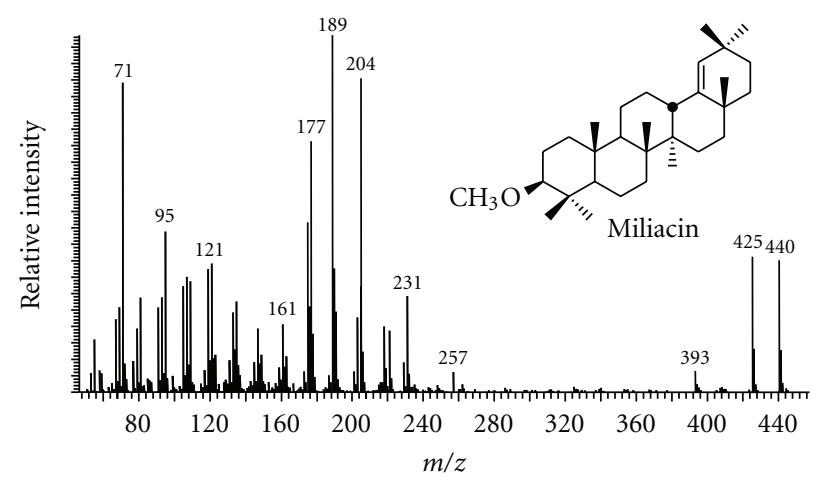

(d)

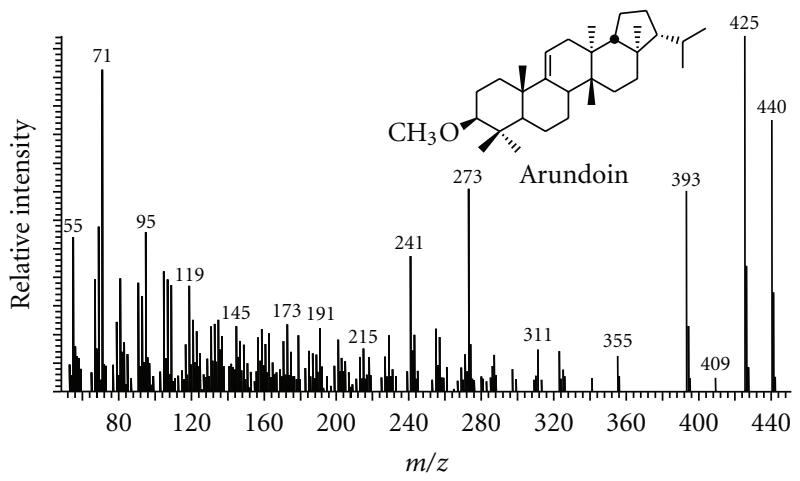

(f)

FIGURE 2: Examples of GC-MS data for triterpenoid methyl ethers in sediment extracts: (a) $m / z 440$ mass fragmentogram for sample GKR08, (b) $\mathrm{m} / \mathrm{z} 440$ mass fragmentogram for sample GKR-02, (c) mass spectrum of sawamilletin, (d) mass spectrum of miliacin, (e) mass spectrum of iso-sawamilletin, and (f) mass spectrum of arundoin.

compared to their parent triterpenols, so a mass balance is not feasible. Nevertheless, their presence in certain sediments may indicate a close input source to that locale, because acetates, like the wax esters, are susceptible to hydrolysis during river transport. The concentrations of the acetates are always 2 to 10 times greater than the hexanoates (e.g., Figure 3(a), Table 1). The highest amounts are observed in the upriver locales and the lowest amounts downriver and in the mangrove bounded estuary. Thus, their source is likely in litter and terrestrial detritus from the grasslands and the deciduous forests and not the mangrove stands.

\section{Conclusion}

Pentacyclic triterpenol derivatives, as the methyl ethers (PTMEs) and alkanoates, were characterized in the sediments of the Cross-River system. The PTMEs that were characterized included germanicol methyl ether (miliacin), $3 \beta$-methoxyfern-9(11)-ene (arundoin), $\beta$-amyrin methyl ether (iso-sawamilletin), and $3 \beta$-methoxytaraxer-14-ene (sawamilletin), while the alkanoates consisted mainly of $\alpha$ - and $\beta$-amyrinyl and lupeyl acetates and hexanoates. These distinct biomarkers are readily extractable from 


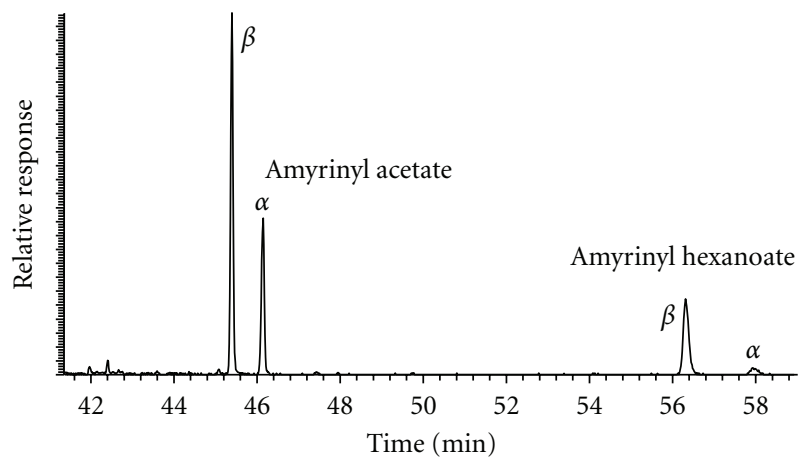

(a)

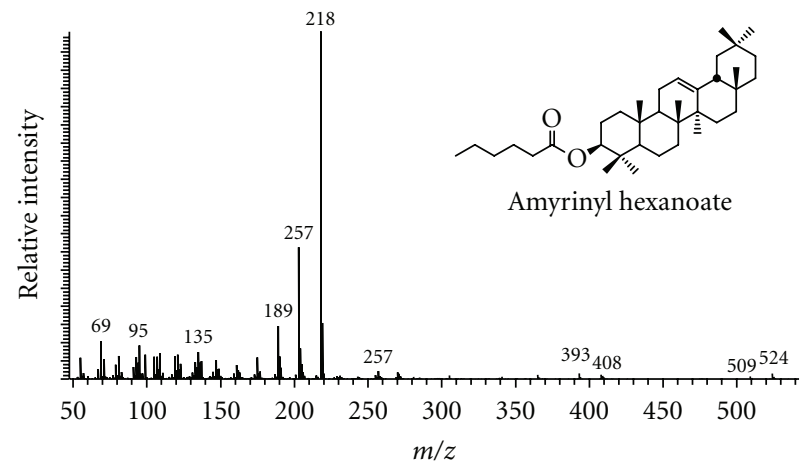

(c)

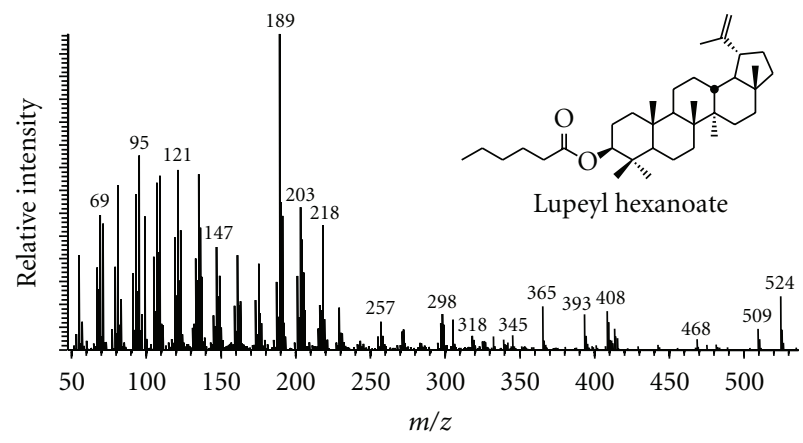

(e)

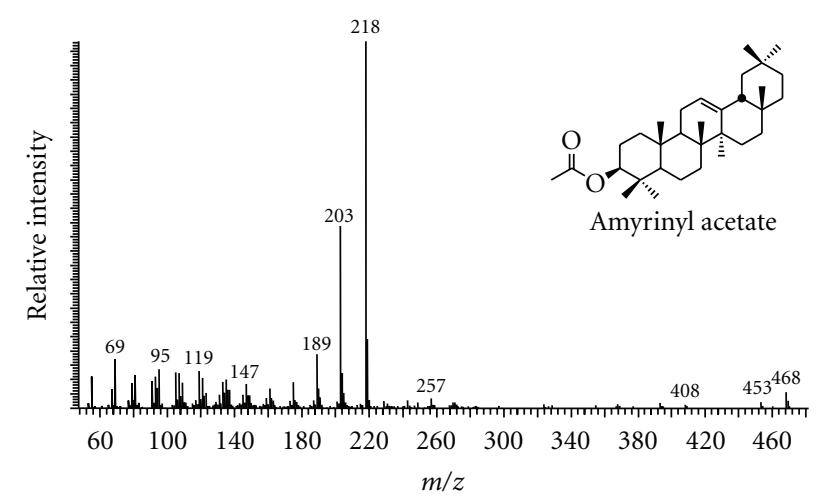

(b)

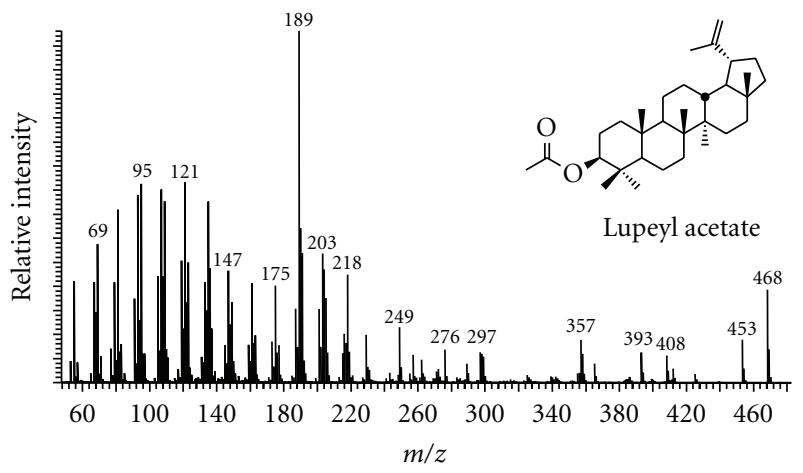

(d)

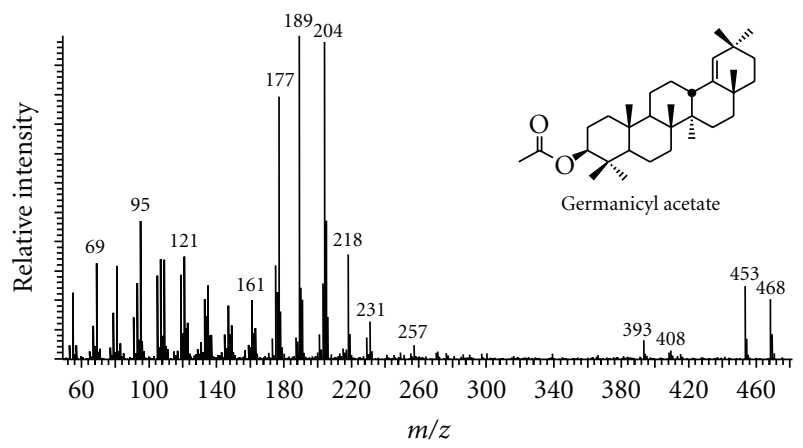

(f)

FIGURE 3: Examples of GC-MS data for triterpenoid esters in sediment extracts: (a) $m / z 218$ mass fragmentogram for amyrinyl esters, (b) mass spectrum of $\beta$-amyrinyl acetate, (c) mass spectrum of $\beta$-amyrinyl hexanoate, (d) mass spectrum of lupeyl acetate, (e) mass spectrum of lupeyl hexanoate, and (f) mass spectrum of germanicyl acetate.

river sediments using polar solvent extraction techniques and are identifiable with routine GC-MS analysis by their characteristic mass spectrometric fragmentation pattern. Pentacyclic triperpenol natural products, their derivatives, and degradation products are excellent chemical metrics for extrapolating the impacts that the river/estuary environment imparts on higher plant organic matter.

\section{References}

[1] P. A. Cranwell, “Organic geochemistry of lacustrine sediments: triterpenoids of higher plant origin reflecting post-glacial vegetational succession," in Lake Sediments and Environmental History, E. V. Harworth and J. W. Lund, Eds., Leicester University Press, Leicester, UK, 1984.

[2] J. O. Grimalt, I. Yruela, C. Saiz-Jimenez, J. Toja, J. W. de Leeuw, and J. Albaiges, "Sedimentary lipid biogeochemistry of an hypereutrophic alkaline lagoon," Geochimica et Cosmochimica Acta, vol. 55, no. 9, pp. 2555-2577, 1991.

[3] B. R. T. Simoneit, "Molecular indicators (biomarkers) of past life," Anatomical Record, vol. 268, no. 3, pp. 186-195, 2002.

[4] J. Jacob, J.-R. Disnar, M. Boussafir, A. L. S. Albuquerque, A. Sifeddine, and B. Turcq, "Pentacyclic triterpene methyl ethers in recent lacustrine sediments (Lagoa do Caçó, Brazil)," Organic Geochemistry, vol. 36, no. 3, pp. 449-461, 2005. 
[5] P. Pant and R. Rastogi, "The triterpenoids," Phytochemistry, vol. 18, no. 7, pp. 1095-1108, 1979.

[6] A. Ghosh, S. Misra, A. K. Dutta, and A. Choudhury, "Pentacyclic triterpenoids and sterols from seven species of mangrove," Phytochemistry, vol. 24, no. 8, pp. 1725-1727, 1985.

[7] S. B. Mahato and S. Sen, "Advances in triterpenoid research, 1990-1994," Phytochemistry, vol. 44, no. 7, pp. 1185-1236, 1997.

[8] J. Jacob, J.-R. Disnar, M. Boussafir, et al., "Onocerane attests to dry climatic events during the Quaternary in the tropics," Organic Geochemistry, vol. 35, no. 3, pp. 289-297, 2004.

[9] J. Jacob, J.-R. Disnar, M. Boussafir, A. L. S. Albuquerque, A. Sifeddine, and B. Turcq, "Contrasted distributions of triterpene derivatives in the sediments of Lake Caçó reflect paleoenvironmental changes during the last 20,000 yrs in NE Brazil," Organic Geochemistry, vol. 38, no. 2, pp. 180-197, 2007.

[10] B. R. T. Simoneit, "Natural products as biomarker tracers in environmental and geological processes," in Selected Topics in the Chemistry of Natural Products, R. Ikan, Ed., pp. 77-126, World Scientific Publishing, Singapore, 2008.

[11] S. D. Killops, J. I. Raine, A. D. Woolhouse, and R. J. Weston, "Chemostratigraphic evidence of higher-plant evolution in the Taranaki Basin, New Zealand," Organic Geochemistry, vol. 23, no. 5, pp. 429-445, 1995.

[12] B. G. K. van Aarssen, R. Alexander, and R. I. Kagi, "Higher plant biomarkers reflect palaeovegetation changes during Jurassic times," Geochimica et Cosmochimica Acta, vol. 64, no. 8, pp. 1417-1424, 2000.

[13] A. I. Rushdi, A. A. DouAbul, S. S. Mohammed, and B. R. T. Simoneit, "Compositions and sources of extractable organic matter in Mesopotamian marshland surface sediments of Iraq. I: aliphatic lipids," Environmental Geology, vol. 50, no. 6, pp. 857-866, 2006.

[14] A. I. Rushdi, A. A. DouAbul, S. S. Mohammed, and B. R. T. Simoneit, "Compositions and sources of extractable organic matter in Mesopotamian marshland surface sediments of Iraq. II: polar compounds," Environmental Geology, vol. 50, no. 8, pp. 1171-1181, 2006.

[15] P. M. Medeiros and B. R. T. Simoneit, "Multi-biomarker characterization of sedimentary organic carbon in small rivers draining the northwestern United States," Organic Geochemistry, vol. 39, no. 1, pp. 52-74, 2008.

[16] D. R. Oros, M. R. bin Abas, N. Y. M. J. Omar, N. A. Rahman, and B. R. T. Simoneit, "Identification and emission factors of molecular tracers in organic aerosols from biomass burningpart 3: grasses," Applied Geochemistry, vol. 21, no. 6, pp. 919940,2006

[17] V. O. Elias, B. R. T. Simoneit, A. S. Pereira, J. A. Cabral, and J. N. Cardoso, "Detection of high molecular weight organic tracers in vegetation smoke samples by high-temperature gas chromatography-mass spectrometry," Environmental Science and Technology, vol. 33, no. 14, pp. 2369-2376, 1999.

[18] A. S. Pereira, D. S. Siqueira, V. O. Elias, B. R. T. Simoneit, J. A. Cabral, and F. R. Aquino Neto, "Three series of high molecular weight alkanoates found in Amazonian plants," Phytochemistry, vol. 61, no. 6, pp. 711-719, 2002.

[19] B. R. T. Simoneit, "Biomarker PAHs in the environment," in The Handbook of Environmental Chemistry, PAHs and Related Compounds, A. H. Neilson, Ed., vol. 3, pp. 175-221, Springer, Berlin, Germany, 1998.
[20] G. A. Wolff, J. M. Trendel, and P. Albrecht, "Novel Monoaromatic triterpenoid hydrocarbons occuring in sediments," Tetrahedron, vol. 45, no. 21, pp. 6721-6728, 1989.

[21] F. Lohmann, J.-M. Trendel, C. Hetru, and P. Albrecht, "C29 Tritiated $\beta$-amyrin: chemical synthesis aiming at the study of aromatization processes in sediments," Journal of Labelled Compounds and Radiopharmaceuticals, vol. 28, no. 4, pp. 377386, 1990.

[22] C. M. Sandison, R. Alexander, R. I. Kagi, and C. J. Boreham, "Early diagenetic transformation of organic matter in a marine-influenced lignite," Organic Geochemistry, vol. 34, no. 8, pp. 1081-1102, 2003.

[23] U. H. Löwenberg and T. H. Künzel, "Investigations on the hydrology of the lower Cross River, Nigeria," Animal Research and Development, vol. 35, pp. 72-85, 1992.

[24] L. E. Etim and E. R. Akpan, "Seasonal variation of metals in the body tissues of Egation radiate from Cross River, Nigeria," African Zoology, vol. 195, pp. 465-472, 1991.

[25] U. K. Enyenihi, O. A. Ayeemi, and A. I. Obiekezie, "Ecological parameters of the mangrove swamp forests of Cross River State; baseline study," in Proceedings of the International Seminar of Petroleum Industries and Nigerian Environment, pp. 228-239, 1987.

[26] E. R. Akpan and J. O. Offem, "Seasonal variation in water quality of the Cross River, Nigeria," Review Tropical Hydrology, vol. 26, pp. 93-103, 1993.

[27] A. E. Asuquo, O. R. Ogri, and E. S. Bassey, "Distribution of heavy metals and total hydrocarbons in coastal waters and sediments of Cross River State, S. E. Nigeria," Tropical Environment, vol. 21, pp. 229-242, 1999.

[28] O. E. Oyo-Ita, B. O. Ekpo, S. U. Umana, and B. R. T. Simoneit, "Predominance of $n$-docosane/docosene as molecular indicators of microbial and recent biogenic organic matter incorporation into surface sediments of Cross River estuary, S.E. Niger Delta of Nigeria," Global Journal of Environmental Sciences, vol. 5, pp. 34-38, 2006.

[29] B. O. Ekpo, O. E. Oyo-Ita, and H. Wehner, "Even-nalkane/alkene predominances in surface sediments from the Calabar River, SE Niger Delta, Nigeria," Naturwissenschaften, vol. 92, no. 7, pp. 341-346, 2005.

[30] T. A. Bryce, M. Martin-Smith, G. Osske, K. Schreiber, and G. Subramanian, "Sterols and triterpenoids-XI. Isolation of arundoin and sawamilletin from cuban sugar cane wax," Tetrahedron, vol. 23, no. 3, pp. 1283-1296, 1967.

[31] C. Djerassi, H. Budzikiewicz, and J. M. Wilson, "Mass spectrometry in structural and stereochemical problems unsaturated pentacyclic triterpenoids," Tetrahedron Letters, vol. 3, no. 7, pp. 263-270, 1962.

[32] K. Nishimoto, M. Ito, S. Natori, and T. Ohmoto, "The structures of arundoin, cylindrin and fernenol. Triterpenoids of fernane and arborane groups of Imperata cylindrica var. koenigii," Tetrahedron, vol. 24, no. 2, pp. 735-752, 1968.

[33] V. O. Elias, B. R. T. Simoneit, A. S. Pereira, and J. N. Cardoso, "Mass spectra of triterpenyl alkanoates, novel natural products," Journal of Mass Spectrometry, vol. 32, no. 12, pp. 1356-1361, 1997.

[34] T. Ohmoto, M. Ikuse, and S. Natori, "Triterpenoids of the gramineae," Phytochemistry, vol. 9, no. 10, pp. 2137-2148, 1970.

[35] S. H. Goh, F. L. Lai, and P. T. Gee, "Wax esters and triterpene methyl ethers from the exocarp of Elaeis guineensis," Phytochemistry, vol. 27, no. 3, pp. 877-880, 1988. 
[36] M. Basyuni, H. Oku, S. Baba, K. Takara, and H. Iwasaki, "Isoprenoids of Okinawan mangroves as lipid input into estuarine ecosystem," Journal of Oceanography, vol. 63, no. 4, pp. 601-608, 2007.

[37] R. Jaffé, A. I. Rushdi, P. M. Medeiros, and B. R. T. Simoneit, "Natural product biomarkers as indicators of sources and transport of sedimentary organic matter in a subtropical river," Chemosphere, vol. 64, no. 11, pp. 1870-1884, 2006.

[38] G. J. M. Versteegh, E. Schefuß, L. Dupont, F. Marret, J. S. Sinninghe Damsté, and J. H. F. Jansen, "Taraxerol and Rhizophora pollen as proxies for tracking past mangrove ecosystems," Geochimica et Cosmochimica Acta, vol. 68, no. 3, pp. 411-422, 2004. 


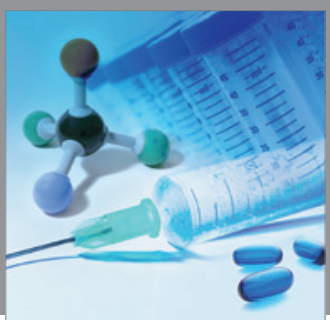

International Journal of

Medicinal Chemistry

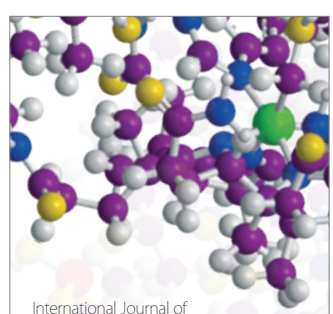

Carbohydrate Chemistry

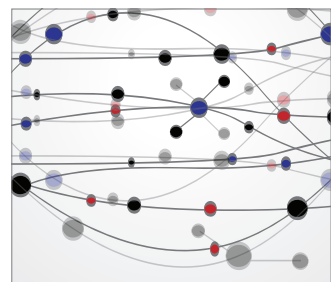

The Scientific World Journal
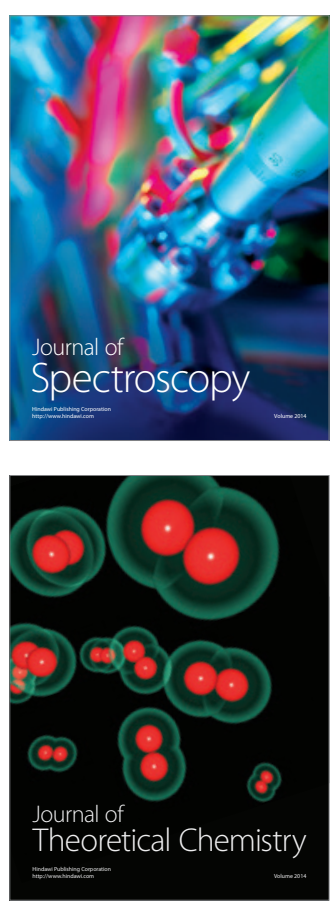
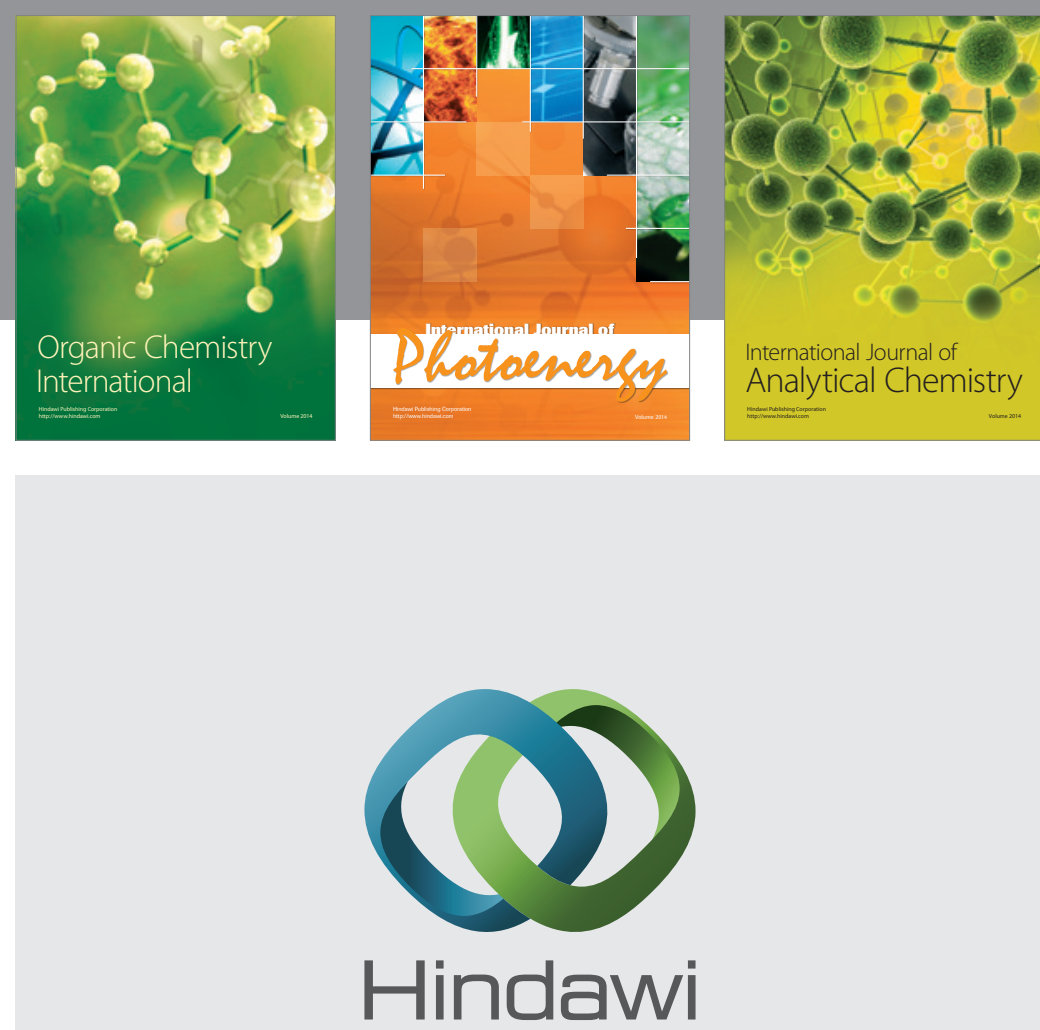

Submit your manuscripts at

http://www.hindawi.com
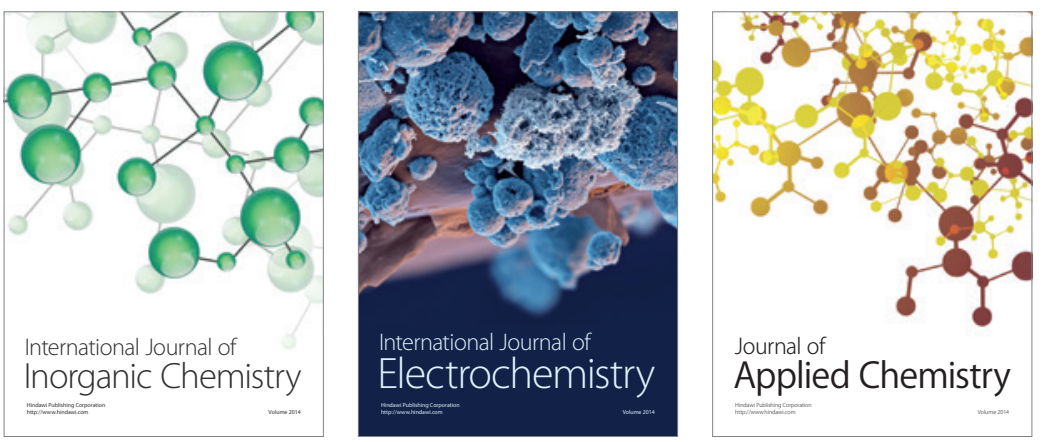

Journal of

Applied Chemistry
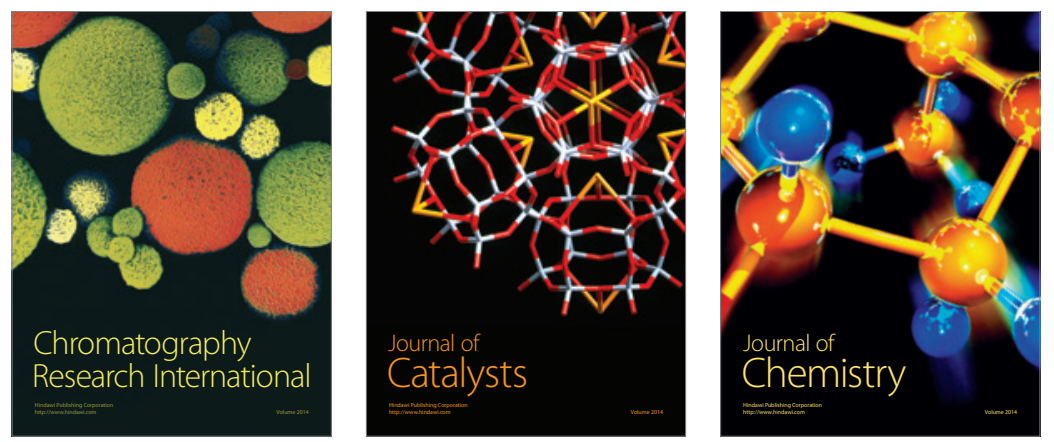
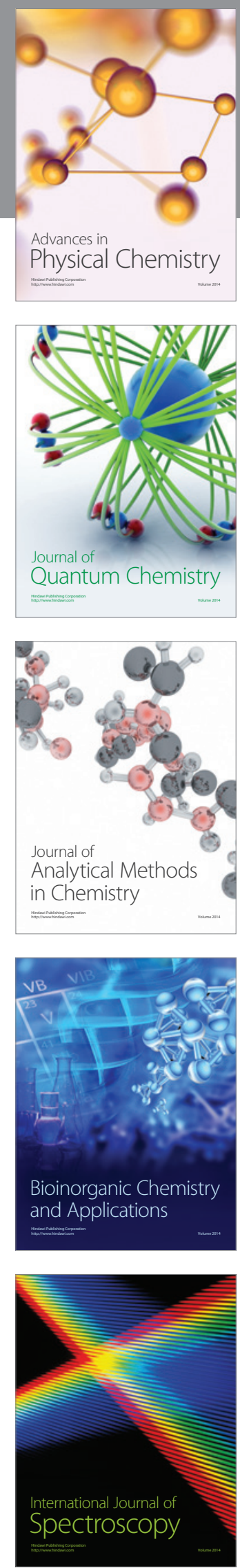